\title{
Lithium dosing strategies during pregnancy and the postpartum period ${ }^{\dagger}$
}

Richard Wesseloo, André I. Wierdsma, Inge L. van Kamp, Trine Munk-Olsen,

Witte J. G. Hoogendijk, Steven A. Kushner and Veerle Bergink

\section{Background}

Lithium is challenging to dose during pregnancy.

\author{
Aims \\ To provide guidance for dosing lithium during pregnancy.
}

\section{Method}

Retrospective observational cohort study. Data on lithium blood level measurements $(n=1101)$, the daily lithium dose, dosing alterations/frequency and creatinine blood levels were obtained from 113 pregnancies of women receiving lithium treatment during pregnancy and the postpartum period.

\section{Results}

Lithium blood levels decreased in the first trimester $(-24 \%, 95 \% \mathrm{Cl}-15$ to -35$)$, reached a nadir in the second trimester $(-36 \%, 95 \% \mathrm{Cl}-27$ to -47$)$, increased in the third trimester $(-21 \%, 95 \% \mathrm{Cl}-13$ to -30$)$ and were still slightly increased postpartum (+9\%, 95\% Cl +2 to +15$)$. Delivery itself was not associated with an acute change in lithium and creatinine blood levels.

\section{Conclusions}

We recommend close monitoring of lithium blood levels until 34 weeks of pregnancy, then weekly until delivery and twice weekly for the first 2 weeks postpartum. We suggest creatinine blood levels are measured to monitor renal clearance.

\section{Declaration of interest}

None.

\section{Copyright and usage}

(c) The Royal College of Psychiatrists 2017.
Lithium is currently the most effective mood stabiliser and widely used as a first-line treatment in bipolar spectrum disorder. It has beneficial treatment effects during manic episodes, is associated with a reduction in suicide risk and is highly effective for relapse prevention. ${ }^{1}$ However, lithium needs to be dosed very carefully because of its narrow therapeutic window. In clinical practice, serum measurements provide crucial guidance to avoid both subtherapeutic $(<0.5 \mathrm{mmol} / \mathrm{L})$ or toxic $(>1.2 \mathrm{mmol} / \mathrm{L})$ blood levels. ${ }^{2-5}$ In addition, it is important to check for renal dysfunction, natrium depletion, dehydration and drug interactions, which can all cause lithium blood level changes. ${ }^{5,6}$ Dosing of lithium is particularly challenging during pregnancy as a result of the normal physiological adaptations of renal function. During pregnancy, increased glomerular filtration rate (GFR) leads to substantial reductions in lithium blood levels and an increased risk of relapse. ${ }^{7}$ Therefore, clinicians are often inclined to increase patients' lithium dose during pregnancy in an effort to maintain adequate prophylactic blood levels. However, later in pregnancy and during the early postpartum period when GFR returns to preconceptional levels, the increased lithium dose can result in toxic lithium blood levels. ${ }^{7,8}$ Toxic lithium levels are concerning not only for the mother, but particularly for the infant in whom the adverse neonatal effects of lithium, such as hypoglycaemia, cardiac arrhythmia, thyroid dysfunction and neonatal lithium toxicity are dose related. ${ }^{9,10}$ Moreover, during the early postpartum period, lithium dosing is challenging because of the very high risk for postpartum relapse $(37 \%, 95 \%$ CI $29-45)$ in women with bipolar disorder. ${ }^{11}$ Therefore, increased therapeutic lithium blood levels are warranted during this high-risk period. Current clinical guidelines provide limited details regarding the optimal approach for monitoring lithium blood levels during pregnancy and the postpartum period. Therefore, in an effort to define an evidence-based strategy for dosing lithium during pregnancy, we

${ }^{\dagger}$ See editorial, pp. 3-4, this issue. investigated a cohort of women ( $n=85$ representing $n=113$ pregnancies) for whom lithium blood levels were measured ( $n=1101)$ longitudinally during pregnancy and the postpartum period.

\section{Method}

\section{Participants}

All women referred to the psychiatric and obstetric out-patient clinics of Erasmus University Medical Centre and Leiden University Medical Centre between January 2003 and May 2015 were evaluated for eligibility to participate in this retrospective observational cohort study. Women were included if they used lithium during pregnancy and at least one lithium blood level measurement was obtained. This study was approved by the Institutional Review Boards of the Erasmus University Medical Centre (MEC-2013-319 ABR NL.45670.078.130) and Leiden University Medical Centre (P15.182).

\section{Data collection and procedures}

This study was conducted and reported in accordance with the STROBE guidelines. ${ }^{12}$ Data were extracted from medical records and processed with data manager OpenClinica 3.5. For each woman, we obtained lithium blood level measurements and all prescribed medication during the period from 25 weeks before conception through 25 weeks postpartum, including the daily lithium dose, dosing alterations and the dosing frequency. We extracted creatinine blood levels to evaluate whether alterations in lithium blood levels were consistent with alterations in the GFR. In addition, we obtained relevant demographic, psychiatric and obstetric data for each woman and her corresponding pregnancies included in the study. Each lithium blood level measurement represented one observation. Lithium citrate (Litarex $564 \mathrm{mg}=6 \mathrm{mmol}$ lithium) dosages were multiplied by 0.395 in order to obtain lithium carbonate prescription equivalents 
( $400 \mathrm{mg}=10.8 \mathrm{mmol}$ lithium). The peripartum time course of lithium blood levels were synchronised between women based upon the date of delivery. Perinatal time windows were defined as preconception (25 weeks preceding the estimated date of conception), first trimester (week 0-13), second trimester (week 14-26), third trimester (week 27-40) and postpartum (25 weeks following delivery).

\section{Statistical analysis}

Data management and descriptive statistics were performed using SPSS version 21.0. Linear mixed-effect modelling was implemented using the procedure MIXED to account for both the nonindependence of repeated lithium blood level measurements within individuals, and differences between women in the observation frequencies and time intervals. Since our primary hypothesis was that pregnancy-induced changes in GFR are responsible for corresponding alterations in lithium blood level, we used lithium blood level as our primary outcome measure, and time (representing gestational age) and lithium dose as our main predictor variables. We also considered the daily frequency of lithium administration, preterm birth ( $<37$ weeks), parity status and number of included pregnancies per woman as candidate predictors. Models with linear, quadratic and cubic effects of time and piecewise models with transition points at conception and delivery were fitted to capture the longitudinal effect of pregnancy-related alterations of GFR on lithium blood levels. We also used a mixed model analysis to study the effect of pregnancy on renal function. Creatinine blood levels were used as the response variable with time as a predictor. Finally, we evaluated the association between renal dysfunction (creatinine $>90 \mu \mathrm{mol} / \mathrm{L}$, dichotomous predictor variable) and lithium blood levels (response variable) among those measurements for which a corresponding creatinine blood level was available within a maximum of 2 weeks prior to obtaining the lithium blood measurement.

Model selection was based on maximum likelihood tests (nested models) and Akaike's information criterion (AIC). Sensitivity analyses were performed to assess if the modelling of lithium blood levels over time was affected by the manner in which we computed the change in lithium blood levels. The standard approach was compared with time-lag models, autoregressive models and change or variance-covariance models. Individual effects in the model were examined using Wald's test with $\alpha=0.05$.

Results
Study characteristics

We identified 89 women that were eligible for study inclusion. Four women were excluded because lithium blood measurements were not available in their medical records as testing was performed at another centre. In total, we included 85 women that were referred to the specialised out-patient university clinics of Rotterdam $(n=59)$ and Leiden $(n=26)$. The most common psychiatric diagnosis was a bipolar spectrum disorder $(n=75$, $88.2 \%)$. The remaining women $(n=10)$ were diagnosed with a schizoaffective disorder, depressive disorder or borderline personality traits. There were 61 women with a single pregnancy, 22 women with two pregnancies, 1 woman with three and 1 woman with five pregnancies. In total, we have evaluated 113 pregnancies and 1101 lithium blood level measurements. In these 113 pregnancies, lithium was either initiated during pregnancy as treatment for an episode $(n=12)$, or as a change in mood stabiliser to reduce the risk of teratogenicity $(n=1)$ or lithium was initiated prior to conception and maintained during pregnancy and the postpartum period $(n=100)$.

Ten women relapsed despite continuous lithium use during pregnancy and the postpartum period. Of these ten women, five relapsed during pregnancy, of whom three also relapsed postpartum. Five women relapsed exclusively in the postpartum period. The parity of the women during each of the included pregnancies was: parity $0(n=54)$, parity $1(n=35)$, parity $2(n=12)$, parity $\geqslant 3(n=12)$. The mean age at the time of delivery was 34.5 (s.d. $=4.21)$ years. In 22 pregnancies $(19.5 \%)$, the delivery was classified as a preterm birth ( $<37$ weeks' gestation). Overall, the deliveries occurred at a median -7 days (IQR -18 to +1 ) prior to the estimated term date.

\section{Course of lithium blood levels in the peripartum period}

The distribution of lithium blood level measurements $(n=1101)$ were as follows: preconception $(n=46)$, first trimester $(n=93)$, second trimester $(n=232)$, third trimester $(n=374)$ and postpartum $(n=356)$. Preconception lithium blood level measurements were unavailable for most pregnancies $(n=89,78.8 \%)$ since the majority of women were referred during the first or second trimester. During pregnancy, lithium citrate (Litarex, slow release) was used during $n=40$ pregnancies and lithium carbonate (Camcolit, Priadel or generic lithium) was used during $n=73$ pregnancies. As shown in Table 1, dosing strategies varied over time. Both the mean and variance of lithium dose was increased, relative to preconception levels, during the second and third trimester and postpartum period. Multiple $(\geqslant 2)$ daily dosing of lithium was used in nearly all pregnancies $(n=111,98.2 \%)$, of which most transitioned to single daily dosing immediately after delivery $(n=79)$ whereas the remainder continued using multiple daily dosing in the postpartum period $(n=32)$. Two women $(n=2,1.8 \%)$ used single daily dosing throughout pregnancy and the postpartum period.

The longitudinal pattern of observed lithium blood levels is presented in Fig. 1. In order to reliably compare lithium blood levels, we normalised lithium blood levels to the total daily dose. The lowest normalised lithium levels occurred during the second trimester, in gestational week 17 . Notably, women were prescribed the highest total mean daily dose during the second trimester (Table 1). A substantial proportion of lithium blood levels were definitely below the therapeutic threshold for effective mood stabilisation $(<0.5 \mathrm{mmol} / \mathrm{L})$ : preconception $(7 / 46,15.2 \%)$, first trimester $(58 / 93,62.4 \%)$, second trimester $(144 / 232,62.1 \%)$, third trimester $(144 / 374,38.5 \%)$ and postpartum $(35 / 356,9.8 \%)$.

Table 1 Lithium dosing strategies in the peripartum period

Dosing scheme, $n$ (\%)

Lithium blood measurements, $n$

Lithium dose (mg), mean (s.d.) 1 daily dose $\geqslant 2$ daily doses

\begin{tabular}{|c|c|c|c|c|}
\hline Preconception & 46 & $925(242)$ & $14(30.4)$ & $32(69.6)$ \\
\hline Trimester 1 & 93 & $922(252)$ & $11(11.8)$ & $82(88.2)$ \\
\hline Trimester 2 & 232 & $1100(357)$ & $15(6.5)$ & 217 (93.5) \\
\hline Trimester 3 & 374 & $1090(323)$ & $10(2.7)$ & $364(97.3)$ \\
\hline Postpartum & 356 & $1034(270)$ & 291 (81.7) & 65 (18.3) \\
\hline
\end{tabular}




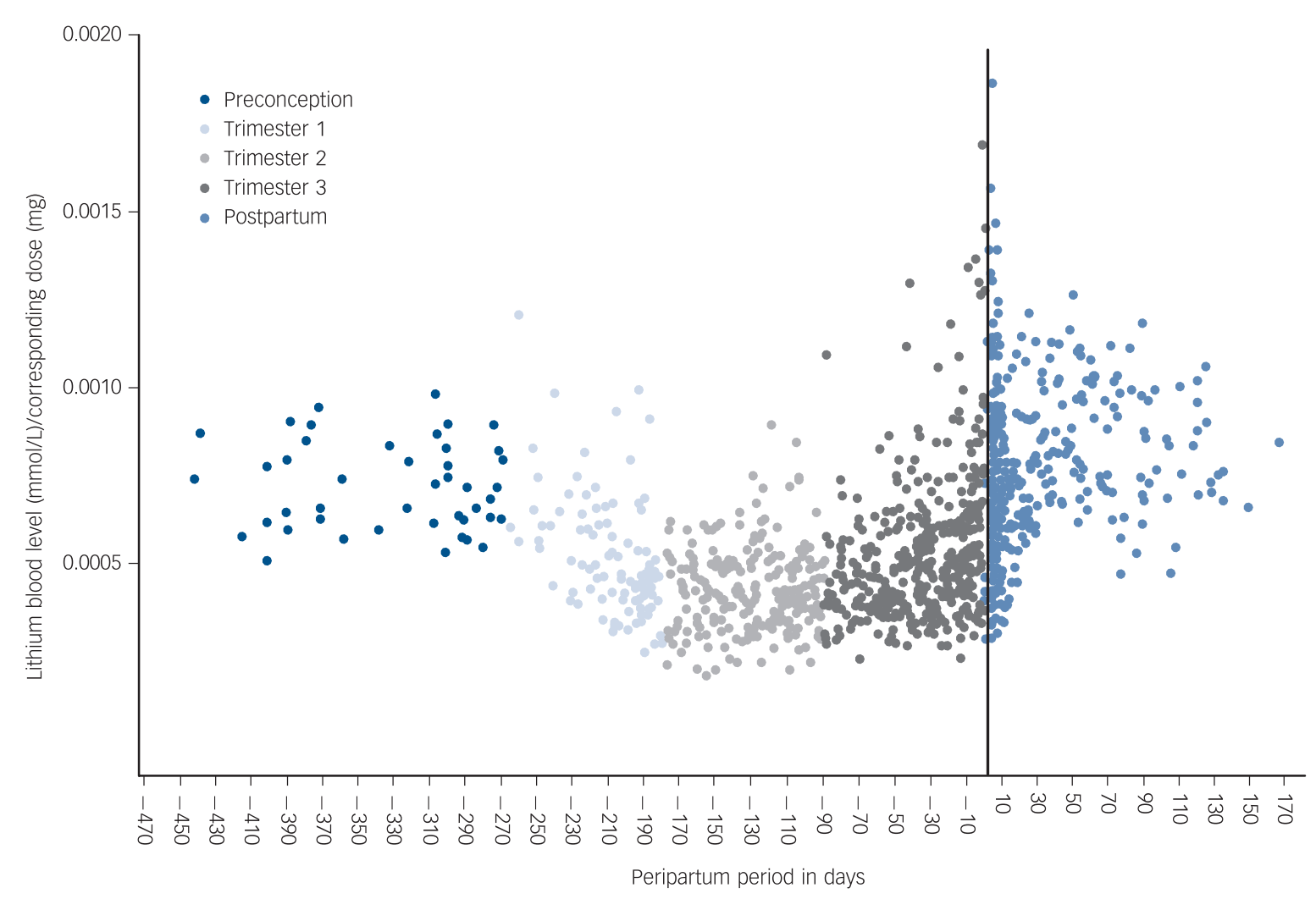

Fig. 1 Course of lithium blood level/dose ratio during the peripartum period.

Delivery is represented by the vertical line (i.e. day zero).

Mixed-effect models with response variable lithium blood levels were fitted, leading to a final model with time (categorical) and the corresponding prescribed lithium dose as predictor covariates (fixed effects). Other candidate predictors, including the frequency of daily lithium administration, preterm birth, parity and the number of included pregnancies per woman, did not significantly improve the performance of the model. The results of the final model are presented in Table 2. At a standardised daily dose of $1000 \mathrm{mg}$, mean lithium blood levels were lower in all trimesters compared with the preconception period. The second trimester was associated with the largest decrease in lithium blood levels $(-36 \%, 95 \% \mathrm{CI}-27$ to -47$)$.

To quantify the influence of delivery on lithium blood levels, we restricted our analysis by comparing lithium blood level measurements during the final week of pregnancy $(n=47)$ and the first postpartum week $(n=186)$. However, including this categorical time covariate within the naive model containing dose as the only predictor covariate did not significantly improve the performance of the model (restricted log likelihood ratio test: $\chi^{2}=3.5$, d.f. $\left.=1, P=0.174\right)$. A graph of the observed data is presented in online Fig. DS1. Sensitivity analyses were performed to evaluate the robustness of the final model. There were no significant differences in the beta estimates between the various models tested. Moreover, model performance did not improve by including centre (Erasmus Medical Centre or Leiden University Medical Centre), number of days between conception and the first lithium blood measurement, or time between the estimated and actual dates of delivery as covariates.

\section{Renal function}

In total, 620 creatinine blood levels were included. In $84 \%$ of all pregnancies $(n=95)$, at least one creatinine measurement was available. A graph of the observed data is presented in online Fig. DS2. We obtained the following mean creatinine blood levels using a mixed model analysis (response variable, creatinine blood levels; predictor covariate, time): preconception $(70 \mu \mathrm{mol} / \mathrm{L}, 95 \%$ CI 66-74), first trimester ( $58 \mu \mathrm{mol} / \mathrm{L}, 95 \%$ CI 50-66), second trimester $(56 \mu \mathrm{mol} / \mathrm{L}, 95 \%$ CI $48-63)$, third trimester $(60 \mu \mathrm{mol} / \mathrm{L}$, 52-67), postpartum $(75 \mu \mathrm{mol} / \mathrm{L}, 95 \%$ CI $67-82)$ (restricted $\log$ likelihood ratio test: $\chi^{2}=293.6$, d.f. $=4, P<1 \times 10^{-5}$ ). Creatinine blood levels exhibited a similar longitudinal pattern as observed for lithium blood levels (reference period-preconception): first trimester $(-17 \%, 95 \%$ CI -11 to -24$)$, second trimester $(-20 \%, 95 \%$ CI -14 to -27$)$, third trimester $(-14 \%, 95 \%$ $\mathrm{CI}-9$ to -21$)$, postpartum $(+7 \%, 95 \% \mathrm{CI}+2$ to +12$)$. We did not observe a significant difference in creatinine blood levels when comparing the first postpartum week with the final week of pregnancy (restricted log likelihood ratio test: $\chi^{2}=3.6$, d.f. $=2, P=0.165)$. In total, $6.5 \%(n=40 / 620)$ of all creatinine

\begin{tabular}{|c|c|c|}
\hline & $\begin{array}{l}\text { Lithium blood level }(\mathrm{mmol} / \mathrm{L}) \text {, } \\
\text { mean }(95 \% \mathrm{Cl})\end{array}$ & $\begin{array}{l}\text { Change (\%), mean } \\
\qquad(95 \% \mathrm{Cl})^{\mathrm{b}}\end{array}$ \\
\hline Preconception & 0.66 (0.61 to 0.71$)$ & Reference \\
\hline Trimester 1 & $0.50(0.40$ to 0.60$)$ & $-24(-15$ to -35$)$ \\
\hline Trimester 2 & 0.42 (0.32 to 0.52$)$ & $-36(-27$ to -47$)$ \\
\hline Trimester 3 & 0.52 (0.43 to 0.62$)$ & $-21(-13$ to -30$)$ \\
\hline Postpartum & $0.72(0.62$ to 0.81$)$ & $+9(+2$ to +15$)$ \\
\hline \multicolumn{3}{|c|}{$\begin{array}{l}\text { a. Linear mixed model analysis. Preconception is reference category. Naive model: } \\
\text { lithium blood level =intercept }+ \text { dose; final model: lithium blood level = intercept+ } \\
\text { dose+time (categorical). Restricted log likelihood ratio test: } \chi^{2}=439.5, \text { d.f. }=4 \text {, } \\
P<0.00001 \text {. } \\
\text { b. Intervals for the \% change are ranges based on the } 95 \% \text { confidence interval of the } \\
\text { lithium blood level. }\end{array}$} \\
\hline
\end{tabular}


blood levels were beyond the upper threshold of $90 \mu \mathrm{mol} / \mathrm{L}$, sug gestive of renal dysfunction. The median of these 40 suprathreshold measurements was $98 \mu \mathrm{mol} / \mathrm{L}$ (IQR 93-109), of which the highest observed value was $130 \mu \mathrm{mol} / \mathrm{L}$. The association of renal dysfunction and lithium blood level was evaluated among the subsample of lithium blood levels for which corresponding creatinine measurements were available $(n=558 / 1101)$. The correlation between these measurements is shown graphically in online Fig. DS3. In this subsample, we observed creatinine blood levels beyond the clinical threshold for renal dysfunction $(>90 \mu \mathrm{mol} / \mathrm{L})$ in $3.8 \%$ of measurements $(n=21 / 558)$ (median $98 \mu \mathrm{mol} / \mathrm{L}$, IQR 92-108). Mixed model analysis revealed that renal dysfunction was significantly associated with elevated lithium blood levels (restricted $\log$ likelihood ratio test: $\chi^{2}=21.2$, d.f. $=1, P=0.00001$ ).

\section{Lithium blood levels and relapse}

Five women relapsed during pregnancy despite continuous use of lithium. Three women had subtherapeutic lithium blood levels $(0.41,0.36$ and $0.31 \mathrm{mmol} / \mathrm{L}$, respectively), one woman discontinued lithium against medical advice and one woman relapsed without a recent lithium blood level. Further, of these five women with relapse during pregnancy, three women also relapsed postpartum (their postpartum blood levels were $0.64,0.58$ and $0.57 \mathrm{mmol} / \mathrm{L}$, respectively). Five women had a relapse exclusively in the postpartum period - one woman had a subtherapeutic lithium blood level $(0.55 \mathrm{mmol} / \mathrm{L})$, and the remaining four women had lithium blood levels of $0.88,0.82,0.76$ and $0.74 \mathrm{mmol} / \mathrm{L}$ (respectively).

\section{Lithium blood levels above the therapeutic window}

Eight women $(n=8 / 85,9.4 \%)$ had lithium blood level measurements above the therapeutic window $(>1.2 \mathrm{mmol} / \mathrm{L}$ ) (Table 3 ). A thorough review of their medical records yielded no evidence to suggest that these measurements were erroneous (for example shortened time interval between administration and blood sampling). Participants 1,5 and 6 used substantially higher lithium doses than the mean prescribed dose in the overall cohort (Table 1$)$. In the majority of women $(n=7 / 8)$, the supratherapeutic lithium blood levels occurred during the week preceding $(n=2)$ or following $(n=5)$ delivery. Notably, four of these seven women had pre-eclampsia and decreased renal function (participants 1, 2, 3 and 7), one was using non-steroidal anti-inflammatory medication (participant 4), another was prescribed a dose with the documented intention to achieve a therapeutic blood level for acute treatment (participant 5) and another had evidence of insufficient anticipation of pregnancy-induced changes in GFR (participant 6). With regard to participant 6 , the difficulty in interpreting blood level fluctuations might have been further exacerbated by the de novo initiation of lithium treatment during pregnancy. Two women (participants 5 and 8 ) were found to have supratherapeutic blood measurements outside the peripartum period. In both cases these women were being treated for acute relapse. Therefore, the physician prescribed a lithium dose with the documented intention of achieving a higher therapeutic blood level.

\section{Discussion}

\section{Main findings}

In this study, we have quantified for the first time the longitudinal pattern of lithium blood levels during the peripartum period using 1101 lithium blood level measurements in 113 pregnancies of 85 women. Lithium blood levels decreased an average of $24 \%$ and $36 \%$ during the first and second trimesters, respectively. In the third trimester and postpartum period, lithium blood levels gradually returned to the preconception level. Interestingly, we did not observe a shift towards higher lithium and creatinine blood levels immediately following delivery.

\section{Comparison of our findings with existing guidelines}

During pregnancy, dynamic changes in GFR necessitate careful monitoring of lithium blood levels, as highlighted in several prominent international guidelines (including ones from the British Association for Psychopharmacology (BAP), ${ }^{13}$ American Psychiatric Association (APA), ${ }^{5}$ Canadian Network for Mood and Anxiety Treatments and International Society for Bipolar Disorders (CANMAT/ISBD) ${ }^{14}$ and Royal Australian and New Zealand College of Psychiatrists (RANZCP)). ${ }^{4}$ Although these guidelines emphasise the importance of close monitoring, they lack specific recommendations regarding the frequency of monitoring and the methodology by which dosing should be adjusted, because of the previously limited available data. The UK National Institute for Health and Care Excellence (NICE) ${ }^{15}$ and the Dutch Association for Psychiatry (NVVP) ${ }^{16}$ guidelines currently recommend monthly monitoring during the initial 7-8 months of pregnancy. Notably, however, our results suggest that more frequent monitoring could be considered because of declining

\begin{tabular}{|c|c|c|c|c|c|c|}
\hline Patient & $\begin{array}{l}\text { Day of blood level } \\
\text { measurement } \\
\text { (delivery is day 0) }\end{array}$ & $\begin{array}{l}\text { Total pregnancy } \\
\text { duration, weeks }\end{array}$ & $\begin{array}{c}\text { Lithium blood } \\
\text { level, } \\
\text { mmol/L }\end{array}$ & $\begin{array}{l}\text { Corresponding } \\
\text { lithium dose, } \\
\text { mg }\end{array}$ & $\begin{array}{l}\text { Creatinine } \\
\text { blood level } \\
(\mu \mathrm{mol} / \mathrm{L})^{\mathrm{a}}\end{array}$ & Plausible cause \\
\hline 1 & -6 & 36 & 1.21 & 1600 & 68 & Pre-eclampsia \\
\hline $2^{b}$ & -4 & $26^{c}$ & 1.90 & $889^{d}$ & $107(\uparrow)$ & Decreased renal function (pre-eclampsia) \\
\hline 3 & +1 & 39 & 1.33 & 1000 & $92(\uparrow)$ & Decreased renal function (pre-eclampsia) \\
\hline 4 & +1 & $30^{c}$ & 1.26 & 800 & 61 & Non-steroidal anti-inflammatory drug prescriptione \\
\hline $5^{f, g}$ & +2 & 41 & 1.38 & 1600 & 56 & Aimed at high target level ${ }^{h}$ \\
\hline $6^{f}$ & +2 & 40 & 1.24 & 2000 & 66 & Insufficiently anticipated on shift in renal function \\
\hline 7 & +2 & $34^{c}$ & 1.21 & 1100 & $119(\uparrow)$ & Decreased renal function \\
\hline 8 & +48 & 40 & 1.27 & 1000 & 53 & Aimed at high target level ${ }^{\text {h }}$ \\
\hline \multicolumn{7}{|c|}{$\begin{array}{l}\text { a. Creatinine levels were obtained within a maximum of } 2 \text { weeks prior to obtaining the lithium blood measurement except for patient } 5 \text { ( }+1 \text { day) and patient } 6 \text { ( }-16 \text { days). } \\
\text { b. Twin pregnancy. This patient had a lithium blood level of } 1.51 \mathrm{mmol} / \mathrm{L} \text { on the subsequent day. } \\
\text { c. Preterm birth. } \\
\text { d. Lithium carbonate equivalent of } 2256 \mathrm{mg} \text { lithium citrate (Litarex). } \\
\text { e. Non-steroidal anti-inflammatory drug use can decrease renal function (indication was pain relief after caesarean section). } \\
\text { f. Lithium treatment initiated during pregnancy. } \\
\text { g. This patient also had an elevated lithium blood level }(1.24 \mathrm{mmol} / \mathrm{L}) 35 \text { days postpartum while treated for the same relapse episode. } \\
\text { h. Higher target blood level because of hospital admission for severe relapse episode. }\end{array}$} \\
\hline
\end{tabular}


blood levels. We found that most women used multiple daily dosing in pregnancy; the rationale for this strategy is to minimise peak lithium levels. ${ }^{10}$ Given the increased risk of non-adherence with multiple daily dosing, we recommend twice-daily dosing rather than more frequent administration. ${ }^{17}$ As expected, lithium and creatinine blood levels showed a highly similar longitudinal pattern throughout the study period. Therefore, the simultaneous evaluation of lithium and creatinine blood levels during pregnancy can be helpful to distinguish between lithium blood level alterations because of fluctuations in renal function versus other factors such as non-adherence.

In line with the current $\mathrm{NICE}^{15}$ and $\mathrm{NVVP}^{16}$ guidelines, we recommend weekly monitoring beginning in the 34th week of pregnancy until delivery. For the majority of women in our study, it was necessary to decrease the prescribed lithium dose in the final months preceding delivery. Especially in those patients with a relatively large decrease in lithium blood levels during the first half of pregnancy, a strong rebound effect in the third trimester should be expected. In these cases, in particular, close monitoring of lithium blood levels during the final phase of the third trimester is clearly warranted. Preconception blood levels and corresponding preconception doses can be used as personalised reference values. Particular attention is required for women presenting with symptoms of preterm birth, pre-eclampsia or other illnesses that can affect renal function. ${ }^{7,9,18}$

Several guidelines suggest decreasing ${ }^{4,5,13}$ or even discontinuing, ${ }^{15,16}$ lithium prophylaxis when a woman exhibits the first signs of labour, because of the association between elevated maternal lithium blood levels and neonatal complications. ${ }^{9}$ This strategy will indeed minimise lithium levels in the newborn, but should also be weighed against the risk of maternal relapse during a period of exceptionally high risk. ${ }^{11}$ Accordingly, we share the opinion of Deligiannidis and colleagues in recommending careful lithium blood level monitoring instead of discontinuation in all cases. ${ }^{7}$ Finally, medications (such as non-steroidal antiinflammatory drugs) that are known to increase lithium blood levels should be avoided. ${ }^{7}$

We recommend relapse prevention prophylaxis in women with bipolar disorder with a higher lithium target level (for example $\geqslant 0.8 \mathrm{mmol} / \mathrm{L}$ ) during the first month postpartum. In our recent meta-analysis ( $n=5105$ pregnancies), 37\% (95\% CI $29-45 \%$ ) of women with a history of bipolar disorder experienced a postpartum relapse. ${ }^{11}$ Given this very high risk of relapse, we hold the view that the benefits of higher lithium target blood levels for the 1-month period following delivery outweighs the potential risks. In our study, we observed that normalisation of renal function can take up to a few weeks after delivery as both mean lithium and creatinine blood levels were higher in the postpartum period than in the preconception period $(+9 \%$ and $+7 \%$ respectively). Therefore, we recommend frequent monitoring (twice weekly) of lithium blood levels for the first 2 weeks postpartum.

\section{Limitations and directions for future research}

Our study has a number of limitations. The observational study design might have introduced information bias. Most women were treated in an out-patient setting. As a result, it is uncertain that a 12-hour interval between dose intake and blood level measurement was always strictly maintained. This effect might have caused higher variability of measured blood levels. Furthermore, some degree of non-adherence might have occurred without our knowledge, particularly during delivery and among women using multiple daily dosing. Finally, preconception blood level measurements were unavailable for most women. Besides the potential risk of neonatal complications, an important concern among clinicians is the potential for lithium-induced teratogenicity. Several older studies have reported that lithium exposure during the first trimester increased the risk of Ebstein's anomaly. ${ }^{19,20}$ In contrast, a recent meta-analysis found no increase in the odds of any congenital malformations, including Ebstein's anomaly. ${ }^{21}$ However, the authors of the meta-analysis also concluded that an accurate estimate of the risk of teratogenicity due to lithium exposure still remains uncertain because of the potential that many of the included studies were inadequately powered to detect such rare events. ${ }^{21}$ Clearly, there is an urgent need for larger studies regarding the potential adverse effects of lithium during pregnancy as well as acute and long-term outcomes for children with in utero lithium exposure. These studies should include women with untreated bipolar disorder as a control group, because bipolar disorder itself seems to be associated with adverse pregnancy outcomes. ${ }^{22}$

\section{Recommendations}

Women of childbearing age requiring mood stabilisation should be given the opportunity to weigh the risks and benefits of lithium treatment during pregnancy and the postpartum period, and to develop an individualised treatment plan together with their healthcare providers in a specialised centre..$^{23-26}$ Women with bipolar disorder are at very high risk for postpartum relapse without medication during pregnancy $(66 \%, 95 \%$ CI $57-75 \%)$, and for some women the benefits of lithium therapy may outweigh the potential risks. ${ }^{11,27}$ However, for those women that are clinically stable without mood stabilisation for an extended period prior to pregnancy, initiation of lithium prophylaxis immediately postpartum is probably sufficient. ${ }^{11,28}$ In this study, we evaluated the pharmacokinetics of lithium during pregnancy and in the period closely surrounding delivery. We have confirmed that lithium dosing is challenging in this period and we have therefore summarised suggestions for dosing strategies.

\section{Pregnancy}

(a) Monitor lithium blood levels frequently (for example once every 3 weeks) until 34 weeks of pregnancy, and then at least once weekly until delivery.

(b) Before 17 weeks of pregnancy, anticipate progressively decreasing lithium levels. Afterwards, expect lithium levels to begin increasing.

(c) Lithium blood levels should be maintained using a therapeutic blood level as low as possible and based on the personal history of the patient. It is therefore important to obtain preconception (reference) lithium and creatinine blood levels, and the corresponding lithium doses.

(d) Consider twice-daily lithium dosing to minimise peak lithium blood levels.

(e) Consider regular creatinine blood level monitoring. A significant decrease in creatinine levels during the first or second trimester suggests a clinically meaningful pregnancyrelated increase in renal function.

(f) Increase the frequency of lithium and creatinine blood level monitoring for women exhibiting signs of preterm birth, pre-eclampsia, dehydration or other illnesses that can affect renal function.

\section{Delivery/postpartum}

(a) Obtain lithium blood levels after delivery and twice weekly during the first 2 postpartum weeks. 
(b) Consider increasing the target therapeutic lithium blood level immediately after delivery and during the first month postpartum to optimise relapse prevention (for example $\geqslant 0.8 \mathrm{mmol} / \mathrm{L}$ ).

(c) Be aware of pharmacokinetic interactions with other medications such as non-steroidal anti-inflammatories.

Richard Wesseloo, MD, André I. Wierdsma, PhD, Department of Psychiatry, Erasmus Medical Centre, Rotterdam; Inge L. van Kamp, MD, PhD, Department of Obstetrics, Leiden University Medical Centre, Leiden, The Netherlands; Trine Munk-OIsen, PhD, National Centre for Register-Based Research, Aarhus University, Aarhus, Denmark; Witte J. G. Hoogendijk, MD, PhD, Steven A. Kushner, MD, PhD Veerle Bergink, MD, PhD, Department of Psychiatry, Erasmus Medical Centre, Rotterdam, The Netherlands

Correspondence: Richard Wesseloo, MD, Department of Psychiatry, Erasmus Medical Centre, 's Gravendijkwal 230, 3000 CA, Rotterdam, The Netherlands. Email: r.wesseloo@erasmusmc.n!

First received 5 May 2016, final revision 12 Sep 2016, accepted 14 Sep 2016

\section{Funding}

TM-O has received funding from $\mathrm{NIMH}$ (grant R01MH104468) and the Lundbeck Foundation Initiative for Integrative Psychiatric Research, Denmark. S.A.K. has received funding from the Netherlands Organization for Scientific Research (the NWO Vidi incentive) the NeuroBasic-PharmaPhenomics consortium and the Dutch Technology Foundation (STW OnTime Program 12197). V.B. is supported by the Netherlands Organization for Scientific Research (the NWO Innovational Research Incentives Scheme).

\section{References}

1 Geddes JR, Miklowitz DJ. Treatment of bipolar disorder. Lancet 2013; 381: 1672-82.

2 Gelenberg AJ, Kane JM, Keller MB, Lavori P, Rosenbaum JF, Cole K, et al Comparison of standard and low serum levels of lithium for maintenance treatment of bipolar disorder. N Engl J Med 1989; 321: 1489-93.

3 Severus WE, Kleindienst N, Seemuller F, Frangou S, Moller HJ, Greil W. What is the optimal serum lithium level in the long-term treatment of bipolar disorder - a review? Bipolar Disord 2008; 10: 231-7.

4 Mitchell PB. Australian and New Zealand clinical practice guidelines for the treatment of bipolar disorder. Aust NZ J Psychiatry 2004; 38: 280-305.

5 Hirschfeld RMA. Practice guideline for the treatment of patients with bipolar disorder. APA Practice Guidelines (2nd edn). APA, 2002

6 National Institute of Health and Care Excellence. Bipolar Disorder: Assessment and Management. NICE Guidelines (CG185). NICE, 2014

7 Deligiannidis KM, Byatt N, Freeman MP. Pharmacotherapy for mood disorders in pregnancy: a review of pharmacokinetic changes and clinical recommendations for therapeutic drug monitoring. J Clin Psychopharmacol 2014; 34: 244-55

8 Blake LD, Lucas DN, Aziz K, Castello-Cortes A, Robinson PN. Lithium toxicity and the parturient: case report and literature review. Int J Obstet Anesth 2008; 17: 164-9.

9 Newport DJ, Viguera AC, Beach AJ, Ritchie JC, cohen LS, Stowe ZN. Lithium placental passage and obstetrical outcome: implications for clinical management during late pregnancy. Am J Psychiatry 2005; 162: 2162-70.
10 Horton S, Tuerk A, Cook D, Cook J, Dhurjati P. Maximum recommended dosage of lithium for pregnant women based on a PBPK model for lithium absorption. Adv Bioinformatics 2012; 2012: 352729.

11 Wesseloo R, Kamperman AM, Munk-Olsen T, Pop VJ, Kushner SA, Bergink V. Risk of postpartum relapse in bipolar disorder and postpartum psychosis: a systematic review and meta-analysis. Am J Psychiatry 2016; 173: 117-27.

12 von Elm E, Altman DG, Egger M, Pocock SJ, Gotzsche PC, Vandenbroucke JP, et al. Strengthening the Reporting of Observational Studies in Epidemiology (STROBE) statement: guidelines for reporting observational studies. BMJ 2007; 335: 806-8.

13 Goodwin GM, Consensus Group of the British Association for Psychopharmacology. Evidence-based guidelines for treating bipolar disorder: revised second edition - recommendations from the British Association for Psychopharmacology. J Psychopharmacol 2009; 23: 346-88.

14 Yatham LN, Kennedy SH, Parikh SV, Schaffer A, Beaulieu S, Alda M, et al. Canadian Network for Mood and Anxiety Treatments (CANMAT) and International Society for Bipolar Disorders (ISBD) collaborative update of CANMAT guidelines for the management of patients with bipolar disorder: update 2013. Bipolar Disord 2013; 15: 1-44.

15 National Institute of Health and Care Excellence. Antenatal and Postnatal Mental Health: Clinical Management and Service Guidance. NICE Guidelines (CG192). NICE, 2014.

16 Dutch Association for Psychiatry. Richtlijn Bipolaire Stoornis [Bipolar Disorder Guideline]. NVVP, 2014.

17 Jensen HV, Davidsen $K$, Toftegaard L, Mellerup ET, Plenge P, Aggernaes $H$ et al. Double-blind comparison of the side-effect profiles of daily versus alternate-day dosing schedules in lithium maintenance treatment of manic depressive disorder. J Affect Disord 1996; 36: 89-93.

18 Lafayette RA, Druzin M, Sibley R, Derby G, Malik T, Huie P, et al. Nature of glomerular dysfunction in pre-eclampsia. Kidney Int 1998; 54: 1240-9.

19 Nora JJ, Nora AH, Toews WH. Lithium, Ebstein's anomaly, and other congenital heart defects (letter). Lancet 1974; 2: 594-5.

20 Weinstein MR, Goldfield M. Cardiovascular malformations with lithium use during pregnancy. Am J Psychiatry 1975; 132: 529-31.

21 McKnight RF, Adida M, Budge K, Stockton S, Goodwin GM, Geddes JR. Lithium toxicity profile: a systematic review and meta-analysis. Lancet 2012 ; 379: 721-8.

22 Bodén R, Lundgren $M$, Brandt L, Reutfors J, Andersen M, Kieler H. Risks of adverse pregnancy and birth outcomes in women treated or not treated with mood stabilisers for bipolar disorder: population based cohort study. BMJ 2012; 345: e7085.

23 Bergink V, Kushner SA. Lithium during pregnancy. Am J Psychiatry 2014; 171 712-5.

24 James $L$, Barnes TR, Lelliott $P$, Taylor $D$, Paton $C$. Informing patients of the teratogenic potential of mood stabilizing drugs: a case note review of the practice of psychiatrists. J Psychopharmacol 2007; 21: 815-9.

25 Yonkers KA, Wisner KL, Stowe Z, Leibenluft E, Cohen L, Miller L, et al. Management of bipolar disorder during pregnancy and the postpartum period. Am J Psychiatry 2004; 161: 608-20.

26 Galbally M, Roberts M, Buist A, Perinatal Psychotropic Review Group. Mood stabilizers in pregnancy: a systematic review. Aust NZ J Psychiatry 2010; 44: $967-77$

27 Gentile S. Lithium in pregnancy: the need to treat, the duty to ensure safety. Expert Opin Drug Saf 2012; 11: 425-37.

28 Bergink V, Bouvy PF, vervoort JSP, Koorengevel KM, Steegers EAP, Kushner SA. Prevention of postpartum psychosis and mania in women at high risk. Am J Psychiatry 2012; 169: 609-15. 